\title{
Polifonia linguística: uma proposta de transposição didática para o ensino da leitura
}

\author{
Linguistic polyphony: a proposal for didactic transposition for teaching reading
}

Tânia Maris de Azevedo

Universidade de Caxias do Sul - Caxias do Sul - Rio Grande do Sul

$\diamond$

\begin{abstract}
Resumo: Este artigo visa a apresentar uma tentativa de transposição didática da Teoria da Polifonia, filiada à Teoria da Argumentação na Língua, de Oswald Ducrot, e da correspondente etapa do Modelo teórico-metodológico para a descrição do sentido do discurso, de Tânia Azevedo, para o ensino da leitura na Educação Básica. Nesse sentido, e por ser derivada da pesquisa Transposição didática da Teoria da Polifonia para o ensino da leitura na Educação Básica, essa proposta parte do pressuposto de que uma leitura competente é aquela capaz de compreender o "jogo" polifônico que constitui o sentido do discurso. A finalidade maior deste estudo é contribuir com a qualificação do processo de desenvolvimento das habilidades de compreensão leitora dos alunos do referido nível de ensino, por meio da concepção polifônica do sentido do discurso, devidamente transposta para o universo escolar. Para tanto, trago à discussão uma atividade de compreensão leitora, cujo principal objetivo é o de pôr à mostra as várias vozes que compõem o sentido de um discurso.
\end{abstract}

Palavras-chave: Teoria da Argumentação na Língua; Teoria da Polifonia; compreensão leitora; transposição didática.

\begin{abstract}
This article intends to present a trial of didactic transposition of the Theory of Polyphony, related to the Theory of Argumentation in Language, by Oswald Ducrot, and to the correspondent stage of the Theoretical-methodological model for description of the sense of discourse, by Tânia Azevedo, for teaching reading in Basic Education. In this sense, and because of derivation from the research Didactic Transposition of Theory of Polyphony for teaching reading in Basic Education, this proposal assumes that a competent reading is the one, which is able to understand the polyphonic "play" that constitutes the sense of discourse. The main aim of this study is to contribute to qualify the process of development of abilities of reading comprehension of students of the referred level, by means of the polyphonic conception of the sense of discourse, duly transposed to the school universe. To do that, I present for discussion an activity of reading comprehension, whose main objective is to show many voices that compose the sense of discourse.
\end{abstract}

Keywords: Theory of Argumentation in Language; Theory of Polyphony; reading comprehension; didactic transposition.

No Brasil, é, no mínimo, lamentável o desempenho da esmagadora maioria dos alunos de nível fundamental, médio, superior e, inclusive, de pós-graduação no que diz respeito à leitura. Se vários processos de avaliação com diversos métodos e instrumentos (PISA, Prova Brasil, ENEM, ENADE, por exemplo) atestam isso, nossa experiência docente comprova diariamente as dificuldades dos alunos em ler e, mais especificamente, em compreender o que é lido, seja o que não está declaradamente expresso, seja, mesmo, o que está manifesto no discurso ${ }^{1}$ escrito.

Pode-se perceber tais dificuldades não só na leitura de discursos científicos, portanto, mais formais e

\footnotetext{
1 Uso aqui o termo discurso, ao invés do comumente usado texto, para ser fiel a Ducrot (1984), teórico de base neste estudo, que diferencia essa entidade linguística concreta de nível complexo do texto, para ele, a correspondente entidade linguística complexa abstrata, construída pelo semanticista para descrever o sentido da entidade concreta.
} 
técnicos, mas também no discurso escolar cotidiano, como nos enunciados que encabeçam atividades didáticas. Na sala de aula, é comum ouvirmos "Profe, o que é pra fazer aqui?" ou "Eu não entendi esse exercício". Por óbvio estou exemplificando somente o que acontece com a compreensão de enunciados escritos bem elaborados e suficientemente claros, uma vez que me refiro unicamente às dificuldades de compreensão dos alunos. Não vou comentar, propositadamente, os enunciados de exercícios ou de provas que apresentam problemas mais ou menos sérios em termos de formulação, pois, primeiro, estaria fugindo à temática deste artigo e, depois, estaria tratando das dificuldades de escrita dos professores, o que pode ser objeto de outro estudo.

As queixas dos professores e a busca por culpados quanto à compreensão leitora dos alunos é regra desde o início do Ensino Fundamental até a pós-graduação, no entanto, esteja em que nível de ensino estiver, não é prática docente comum investir tempo na elaboração e proposição de atividades didáticas que promovam o desenvolvimento, pelo aluno, dessa habilidade e das outras que a compreensão pressupõe. Os discursos levados à sala de aula continuam sendo mote para o "estudo" dos conteúdos gramaticais que povoam os planos de ensino; as questões ditas de compreensão constantes de diferentes livros didáticos, não só os destinados ao estudo da língua portuguesa, no mais das vezes, exigem apenas localização e cópia de segmentos do discurso ou, ainda a título do que intitulam compreensão, solicitam aos aprendizes opiniões e julgamentos de valor.

Nesse cenário nada promissor em termos de aprendizagem, seja da própria leitura, seja do conhecimento social, histórica e cientificamente produzido e quase sempre veiculado pela escrita, é que se insere este artigo: uma tentativa de transposição didática de uma teoria semântico-linguística - a Teoria da Polifonia, de Oswald Ducrot - para a qualificação do desenvolvimento de habilidades que a compreensão leitora requer.

Para tanto, convido o leitor a refletir sobre: (a) o processo da leitura e de sua aprendizagem; (b) a transposição didática de um saber científico para o ambiente escolar no que diz respeito não à formação de conceitos, mas ao desenvolvimento de habilidades semânticolinguísticas; (c) a concepção polifônica do sentido, desde o prisma da polifonia linguística proposta por Oswald Ducrot e integrante de sua Teoria da Argumentação na Lingua (TAL); e (d) um exemplo de formulação de questões de compreensão leitora com base nos pressupostos dessa Teoria da Polifonia (TP) como substitutivas das questões propostas por um livro didático destinado ao $6^{0}$ ano do Ensino Fundamental.

\section{Leitura: algumas ponderações}

Começo por trazer à discussão algumas das ideias sobre a aprendizagem da leitura constantes do documento que define as bases curriculares para o ensino e a aprendizagem da língua materna no nível fundamental no Brasil, os Parâmetros Curriculares Nacionais (PCN) de Língua Portuguesa para os anos finais do Ensino Fundamental.

Não é possível esperar que os textos que subsidiam o trabalho das diversas disciplinas sejam auto-explicativos. Sua compreensão depende necessariamente do conhecimento prévio que o leitor tiver sobre o tema e da familiaridade que tiver construído com a leitura de textos do gênero. É tarefa de todo professor, portanto, independentemente da área, ensinar, também, os procedimentos de que o aluno precisa dispor para acessar os conteúdos da disciplina que estuda. (BRASIL, 1998, p. 32)

Selecionei esse trecho do documento, porque, mesmo sendo o objeto de estudo deste artigo a leitura do ponto de vista linguístico, é preciso ter em mente que, para o aprendiz, uma leitura proficiente é um dos requisitos (senão o primeiro) para o acesso à informação em todas as áreas do conhecimento e, portanto, em todos os componentes curriculares. Isso implica dizer que o aprendizado da leitura, o desenvolvimento das habilidades que esse processo exige, não pode ser incumbência única da disciplina de língua materna. Por óbvio, a leitura não é essencial apenas nos bancos escolares, mas também e com maior importância ainda na construção da cidadania do aprendiz.

Dito isso mais a título de esclarecimento introdutório, vou me ater, no presente estudo, à aprendizagem escolar da leitura e, mais especificamente, aquela a ser realizada na disciplina de Língua Portuguesa.

Em vista do objetivo que tenho aqui de propor a polifonia linguística como potencializadora do desenvolvimento das habilidades de compreensão leitora, preciso tratar de ver como os PCN concebem a leitura mais qualificada, não mais em termos de alfabetização e de compreensão do que está manifestamente expresso no discurso, mas uma leitura idealmente compatível com os anos finais do Ensino Fundamental.

Segundo os PCN (BRASIL, 1998:70), o "leitor competente é capaz de ler as entrelinhas, identificando, a partir do que está escrito, elementos implícitos, estabelecendo relações entre o texto e seus conhecimentos prévios ou entre o texto e outros textos já lidos".

Pois muito bem, é justamente pelo fato de a concepção polifônica do sentido, de Oswald Ducrot, pôr à mostra os vários pontos de vista mobilizados pelo 
locutor na produção do discurso, assim como a posição do locutor frente a cada um desses pontos de vista, que penso ser possível ao menos potencializar o desenvolvimento, por parte do aprendiz, da compreensão leitora pelo uso didático de tal Teoria.

Voltando ao que dizem os PCN acerca da "boa" leitura, ao final do nível fundamental de ensino, é esperado do aluno que:

- leia, de maneira autônoma, textos de gêneros e temas com os quais tenha construído familiaridade:

- selecionando procedimentos de leitura adequados a diferentes objetivos e interesses, e a características do gênero e suporte;

- articulando o maior número possível de índices textuais e contextuais na construção do sentido do texto, de modo a:

$[\ldots]$

- extrair informações não explicitadas, apoiando-se em deduções. (BRASIL, 1998, p. 49-50)

Creio que, se a concepção polifônica for constantemente e bem trabalhada nas atividades de compreensão leitora, será possível, inclusive, ultrapassar, ao final desse nível, o que preveem os PCN. Em quê? Pela polifonia semântico-linguística (e não é por acaso que Ducrot, reiteradas vezes, a denomina assim), o leitor poderá compreender as "informações não explicitadas" (e, assim, o sentido do discurso escrito) sem precisar recorrer a deduções e inferências, pois, como a polifonia está integrada ou constitui o próprio sistema linguístico, as palavras, os enunciados e as relações interenunciados já evidenciam o que está dito sem estar explicitamente escrito.

É interessante perceber que os PCN (BRASIL, 1998, p. 56-57) já apontam para a necessidade de ensinar o aluno a ler a polifonia que constitui os discursos de uma língua, visto que já a inclui no item intitulado "CONCEITOS E PROCEDIMENTOS SUBJACENTES ÀS PRÁTICAS DE LINGUAGEM - Leitura de textos escritos", como se pode ver no trecho abaixo.

\section{$[\ldots]$}

levantamento e análise de indicadores lingüísticos e extralingüísticos presentes no texto para identificar as várias vozes do discurso e o ponto de vista que determina o tratamento dado ao conteúdo, com a finalidade de:

- confrontá-lo com o de outros textos;

- confrontá-lo com outras opiniões;

- posicionar-se criticamente diante dele.

Quero crer que as "várias vozes do discurso" que o documento refere sejam os pontos de vista, os enunciadores (na terminologia ducrotiana) atualizados no discurso pelo locutor, e o "ponto de vista" mencionado corresponda às atitudes do locutor em relação a cada um dos enunciadores mobilizados. Esse, em síntese, seria o processo constituidor do sentido para Ducrot (1987) que discutiremos mais adiante.

$\mathrm{O}$ que trouxe dos PCN me serviu para justificar a proposta de transposição didática da Teoria da Polifonia para uma maior qualificação do desenvolvimento da habilidade de compreensão de discursos escritos e, com isso, a leitura como um todo. Cabe-me agora explicar a razão de ter me reportado até aqui ao conceito de compreensão leitora e de ter deixado, propositadamente, aberta a possibilidade de que esse conceito não seja visto como semelhante ou mesmo substituto do conceito de leitura que subjaz a este estudo.

Entendo por leitura o processo interativo do sujeito com o discurso escrito, com o propósito de constituir sentido no que está sendo lido. Se não falo na interação leitor-autor, comumente referida e defendida, é pelo fato de crer que o leitor não tenha acesso ao autor, somente ao discurso que foi por este realizado de forma escrita. Posso dizer que minha concepção de leitura se filia à perspectiva enunciativa de estudos linguísticos e, por isso, evoco o que diz Teixeira (2005:199) acerca da leitura como ato enunciativo: "Conceber a leitura como ato enunciativo é concebê-la como um ato do sujeito-leitor, mediante o qual ele estabelece uma relação com o texto para produzir sentido no momento da leitura.".

Para mim, esse ato de constituição de sentido é composto por três níveis ordenada e hierarquicamente dispostos, isto é, sem que o primeiro seja concluído, não há como passar ao segundo e assim sucessivamente. São eles: (1) decodificação, a decifração do código escrito, o reconhecimento e a combinação de letras em palavras e enunciados; (2) compreensão, a constituição, de modo analítico e sintético, do sentido das inter-relações das unidades de composição do discurso e do discurso como uma totalidade semântico-enunciativa; (3) interpretação, o estabelecimento de relações entre o conteúdo temático do discurso e os contextos de produção e de recepção desse discurso.

Espero ter deixado claro que, ao me referir à possibilidade de qualificação que a concepção polifônica do sentido pode conferir ao desenvolvimento da compreensão leitora, estou me reportando às relações e inter-relações semânticas internas ao discurso lido, ao entendimento do sentido de enunciados, das relações entre eles e do discurso como um todo. Nesse sentido, subdivido o nível de compreensão em dois outros: (a) a compreensão analítica, em que o leitor "decompõe" a totalidade semântica que é o discurso em partes (enunciados, palavras) com o intuito de examinar cada uma e as relações de umas com as outras, a fim de compreender o todo; e (b) a compreensão sintética, na 
qual o leitor "recompõe" a unidade do discurso pela reconstituição das inter-relações semânticas previamente compreendidas por análise.

Não constitui objeto de investigação da semântica ducrotiana o extralinguístico, logo, o que for externo ao discurso escrito, por isso não pretendo, neste artigo, tratar sobre o nível da interpretação assim como o concebo.

Caminhando para a consecução do objetivo deste trabalho, passo a tratar, agora, do conceito de transposição didática particularmente aplicado ao ensino de língua materna.

\section{Transposição(?) didática: proposta de revisão do conceito}

Permita-me o leitor fazer aqui um parênteses antes de abordar o conceito objeto deste tópico, já que preciso apresentar alguns pressupostos de base para poder propor a revisão que tenho em mente.

O primeiro deles é o conceito de aprendizagem. Como eu dizia em 2010,

'aprendizagem', aqui, é concebida como o desenvolvimento de competências/habilidades essenciais (como as de observar, comparar, classificar, analisar, sintetizar, interpretar, criticar, definir, explicar) ao acesso e à compreensão das informações, à formação de conceitos, à construção de conhecimentos e à constituição do saber. (AZEVEDO, 2010, p. 203)

Pensando aprendizagem como esse multifacetado processo, não há como conceber a aprendizagem de língua materna como a memorização de regras gramaticais ou como fruto da repetição de exercícios de classificação, conjugação ou flexão. Pois bem, para mim, a aprendizagem de uma língua é o processo de desenvolvimento de quatro habilidades complexas, porque compostas de várias outras habilidades: compreender o que é enunciado oralmente, falar, ler e escrever.

Pozo (2002) denomina o desenvolvimento de habilidades ou de estratégias como aprendizagem de procedimentos, que, segundo ele, diz respeito a um "saber fazer" utilizado para realizar ações como as de escrever, ler, falar.

Diferentemente de disciplinas curriculares como História, Geografia, Biologia, Química que pressupõem uma aprendizagem voltada à formação de conceitos, a aprendizagem de língua, materna e/ou estrangeira, exige o desenvolvimento de habilidades. De que adianta formar conceitos como os de língua, frase, verbo, advérbio para aprender a usar uma língua de forma oral e escrita?

Dito isso, é preciso diferenciar as aprendizagens que são imprescindíveis ao professor e ao usuário de língua. Ao professor, é fundamental formar conceitos que alicerçam a Linguística, bem como a aprendizagem e o ensino de língua. Já, para o usuário, nenhum conceito linguístico faz com que fale, leia e/ou escreva uma língua; o que o torna proficiente é sua exposição a várias e diversas situações enunciativas orais e/ou escritas, a fim de que desenvolva suas habilidades de utilização adequada e apropriada da língua conforme seu(s) interlocutor(es) e seu(s) propósito(s) em cada circunstância de discurso.

Todos esses comentários e essas distinções me foram necessários para justificar as razões que me levam a ver a transposição didática, tal como proposta por Yves Chevallard, não suficientemente apropriada ao ensino de língua. Começo, então, minha proposta de revisão desse conceito.

O matemático Yves Chevallard é a referência mais conhecida quando se estuda a transposição didática. Para esse autor (1991), a transformação do saber científico ou técnico para o saber escolar é o que ele chama de transposição didática. Consoante Chevallard (1991), ao ser transposto de um contexto científico ou técnico para o âmbito do ensino regular um conceito passa por "deformações", mudanças para que seja compreensível ao aprendiz e, nesse processo, é adaptado e adquire sentidos compatíveis com o contexto em que será aprendido, diferentemente do entendimento que tinha na investigação que lhe deu origem.

Para Álvarez (2005, p. 50), a transposição didática designa,

[...] las transformaciones que experimenta un determinado saber cuando se expone didácticamente, con respecto a su origen científico e incluso en el proceso de invención, ya que los contenidos experimentan modificaciones en el camino que va de los discursos de invención a los discursos de exposición especializada, a los discursos de difusión y de vulgarización y a los discursos escolares.

A transposição didática de que Chevallard e Álvarez falam se atém a conceitos científicos ou técnicos modificados para se tornarem conceitos a serem ensinados, a serem formados por alunos na escola. Entretanto, como disse anteriormente, aprender a utilizar proficientemente uma língua nas modalidades oral e escrita não depende da formação de conceitos, mas do desenvolvimento de habilidades. Assim sendo, esse modelo de transposição pode não se aplicar ao ensino de língua.

Com base no raciocínio apresentado, proponho uma "revisão" do conceito de transposição didática quando aplicado ao ensino de língua. Para que tal proposta faça sentido, é preciso considerar dois grandes cenários: o da pesquisa e o do ensino.

Sabe-se muito bem que as teorias científicas são fruto de pesquisa, e o conhecimento produzido nesse contexto 
corresponde ao que Chevallard denomina saber sábio. No caso das teorias linguísticas aplicadas ao ensino de língua, há duas dimensões a serem singularizadas: a da formação de professores de língua e a do ensino de língua na Educação Básica.

A singularidade de cada dimensão está na natureza didática de aplicação das teorias linguísticas, em razão de ser totalmente diferente o saber a ser ensinado em cada uma delas. Na formação de professores há ainda que distinguir dois papéis exercidos por esses profissionais: o de docente e o de usuário da língua em questão.

A formação do professor de língua, no que diz respeito à docência, não pode prescindir do estudo das teorias linguísticas, e nessa dimensão a transposição didática de Chevallard se aplica, pois os conceitos dessas teorias precisarão sair do contexto científico de sua produção para o contexto de ensino, precisam ser transpostos do saber sábio ao saber a ser ensinado. No entanto, para que possa ser um verdadeiro mediador da aprendizagem de uma língua, para que possa efetiva e eficazmente promover o desenvolvimento, pelo aluno, das habilidades que o uso da língua pressupõe, o professor precisa, além de aprender a transformar esse saber teórico em um meio para que seu aluno utilize eficazmente a língua, ser um usuário proficiente dessa língua; não basta saber falar sobre ela, classificá-la, analisá-la sintaticamente ou saber falar sobre as teorias linguísticas: produzir um discurso coerente e coeso é bem diferente de, pela Linguística do Texto, definir coerência e coesão.

Como esclarece Pozo (2002, p. 228 - grifos do autor),

[...] em muitos âmbitos, a educação e a formação explicam o que se deve fazer mas não ensinam como fazê-lo. Os aprendizes queixam-se de que a formação é muito teórica e pouco prática. Os mestres, de que os aprendizes não sabem aplicar o que, tão claramente, lhes é explicado. Entre o saber dizer e o saber fazer há um salto que não podemos deixar que o aprendiz dê sozinho.

Não me parece haver como ensinar alguém a dirigir um automóvel ou a cozinhar, por exemplo, sem que se seja um motorista ou um cozinheiro habilidoso, visto que, para o desenvolvimento de habilidades, falar sobre elas ou sobre o que se deve fazer para desenvolvê-las não é suficiente, nem necessário. A título de evidência basta observarmos a aprendizagem oral da língua materna: como uma criança aprenderia a falar e a compreender o que outros falantes dizem se estes não fossem minimamente proficientes no uso dessa língua.

Aliás, como usuários, aluno e professor precisam, proporcionalmente, desenvolver as mesmas habilidades. Se é assim, e, conforme disse Pozo, há um grande salto entre o saber dizer e o saber fazer, para o saber a ser ensinado ao usuário de uma língua, o conceito de transposição didática de Chevallard não se aplica, pois não há como transformar habilidades em conceitos. Aqui reside minha proposta de revisão desse conceito.

A finalidade didática das teorias linguísticas no processo de aprendizagem do uso de uma língua (quer oral, quer escrito) não é mais o de fornecer os conceitos e princípios descritivos/explicativos da língua e, por isso, ser transposta didaticamente ao contexto educativo formal, mas o de se transformar didaticamente em uma espécie de "ferramenta" que potencialize, por meio de atividades (problemas e exercícios), o desenvolvimento das habilidades indispensáveis a essa aprendizagem.

Dito de outra forma: para o ensino de língua, não basta adaptar ou, como diz Chevallard (1990) "deformar" o conhecimento cientificamente produzido com o intuito de simplificá-lo e torná-lo possível de ser aprendido pelo aluno, é mais do que isso, trata-se de transformar uma teoria científica em "instrumento" para o desenvolvimento de habilidades.

Evidentemente, não pretendo nem me é permitido neste artigo aprofundar essa proposta, mas apenas lançála à discussão, com o propósito de vir a torná-la objeto de futuras investigações. Minha ideia é a de que, para o desenvolvimento de habilidades, o que Chevallar (1991) entende como transposição didática venha a ser concebido como transformação didática: o saber sábio, por um processo de adaptação e reconfiguração, transformando-se em saber a ser ensinado, este como mecanismo potencializador de aprendizagens que requeiram o desenvolvimento de habilidades.

É nessa direção que vislumbro trabalhar didaticamente com a polifonia linguística voltada ao desenvolvimento, pelos usuários de uma língua (alunos e/ou professores em formação), das habilidades implicadas na constituição do sentido dos discursos lidos, isto é, na compreensão leitora.

\section{Polifonia linguística: transformação didática para a compreensão leitora}

Antes de retomar brevemente a Teoria da Polifonia, de Oswald Ducrot, devo alertar o leitor de que me servirei neste artigo da concepção polifônica do sentido como Ducrot a descreve nas obras $O$ dizer e o dito (1987) e Polifonía y argumentación (1990). Faço isso por dois motivos: (a) por crer que essa versão da Teoria pode indiscutivelmente colaborar para o desenvolvimento da compreensão leitora, já que põe à mostra os pontos de vista atualizados pelo locutor em cada enunciado de um discurso, bem como a posição deste em relação a cada ponto de vista; e (b) pelo fato de a última versão da TP de que se tem notícia, a Teoria Argumentativa da Polifonia, 
de Oswald Ducrot e Marion Carel, estar sendo ainda revista e em (re)formulação.

No primeiro capítulo da obra Les mots $d u$ discours (1980), Ducrot, afirmando que a descrição da enunciação constitui o sentido do enunciado, vê nessa descrição, conforme Azevedo (2011), a necessidade de diferenciar as seguintes funções discursivas: (a) locutor, autor das palavras; (b) enunciadores, agentes dos atos ilocucionários ${ }^{2}$; (c) alocutário, a quem é dirigida a enunciação do locutor; e (d) destinatário, a quem se dirigem realmente os atos ilocucionários produzidos pelos enunciadores. Tal diferenciação permite-lhe pôr à mostra as "várias vozes que se manifestam no enunciado e lhe conferem sentido" (AZEVEDO, 2011, p. 65). Eis aqui a primeira aparição e definição do conceito de polifonia, bem como a correspondente concepção polifônica do sentido que, a partir daí, compõe a Teoria da Argumentação na Língua.

Devido ao fato de se opor veementemente à tese da unicidade do sujeito como autor e responsável pelo que é dito em um enunciado, Ducrot retoma e reformula sua Teoria da Polifonia na obra $O$ dizer e o dito (1987). Segundo o que ele propõe, a origem da enunciação é conferida a um ou a diversos sujeitos, dentre os quais se distinguem os locutores e os enunciadores. Locutor é definido como o responsável pelo enunciado, logo, pelo seu sentido; enunciador é um ser do discurso cuja expressão é feita sem que necessariamente lhe sejam atribuídas palavras precisas; se o enunciador fala "é somente no sentido em que a enunciação é vista como expressando seu ponto de vista, sua posição, sua atitude, mas não, no sentido material do termo, suas palavras" (DUCROT, 1987, p. 192).

Mais uma diferenciação é indicada por Ducrot (1987), aquela entre locutor e autor empírico. O primeiro é uma "ficção discursiva" que o próprio enunciado manifesta como responsável pelo sentido nele constituído; o segundo é o ser no mundo, o sujeito de carne e osso que articula psicofisiologicamente o enunciado. Exemplificando: no enunciado dito por mim Eu não acredito que Maria disse ter sido aprovada, há dois locutores: aquele indicado pela primeira pessoa e Maria, no entanto há apenas um autor empírico, no caso eu que proferi, oralmente ou por escrito, o enunciado.

Nesse momento da Teoria da Polifonia, descrever semanticamente um enunciado pressupõe: (a) identificar no enunciado o locutor e os enunciadores atualizados pelo

\footnotetext{
2 Nessa época, é explícita a relação de Ducrot com a pragmática anglo-saxã, de Austin e Searle. Já a partir de O dizer e o dito (1987), o semanticista se afasta e chega a negar esses pressupostos teóricos, pois se torna cada vez mais convicto de que a língua não tem um valor informativo: para ele, não há como conferir um juízo de valor aos enunciados de uma dada língua, não havendo, portanto, enunciados verdadeiros ou falsos.
}

locutor; (b) localizar o ponto de vista de cada enunciador; e (c) analisar qual é a atitude do locutor em relação a cada enunciador.

Em 1990, na obra que divulga as conferências que realizou, em Cali, na Colômbia, Ducrot apresenta algumas reformulações de sua concepção polifônica do sentido, associando à Teoria dos Topoi a Teoria da Polifonia.

Reiterando sua oposição à tese da unicidade do sujeito, Ducrot (1990:16), no primeiro capítulo de Polifonía y argumentación, diz que "en un mismo enunciado hay presentes varios sujetos con status lingüísticos diferentes.". São três as funções discursivas a que Ducrot se refere como "sujeitos com status linguísticos diferentes": a de sujeito empírico, a de locutor e a de enunciador. Como referi em 2011, me parece significativo

$$
\begin{aligned}
& \text { que conceitos da versão anterior da teoria polifônica } \\
& \text { (1980-1987), como os de vários sujeitos ou tipos de } \\
& \text { personagem, são agora apresentados como funções } \\
& \text { que dizem respeito à ideia de sujeito falante. Isso } \\
& \text { parece apontar para o fato de tais conceitos serem } \\
& \text { formulações de caráter metodológico, ou seja, criadas } \\
& \text { como ferramentas para a descrição do sentido, e [...] } \\
& \text { aí está o grande avanço dessa etapa da Teoria da } \\
& \text { Polifonia em relação às anteriores, além, é claro, de } \\
& \text { sua associação à TAL para tornar mais profunda e } \\
& \text { precisa a descrição semântica. }
\end{aligned}
$$

O que Ducrot (1990) chama de sujeito empírico não difere substancialmente do que dizia sobre esse mesmo conceito em 1987, é o autor efetivo, o produtor do enunciado. Por não ser interno ao enunciado (e, portanto, à língua), o sujeito empírico não é objeto de descrição semântica, uma vez que integra as condições externas da produção desse enunciado. Para Ducrot (1990), não é tarefa da semântica linguística estudar o sujeito empírico que produziu um enunciado, mas sim analisar e descrever o sentido do enunciado, o que o enunciado diz.

A função locutor é, na obra em questão, definida como a que faz com que o locutor seja o "presunto responsable de la enunciación en el enunciado mismo." (DUCROT, 1990, p. 17 - grifos do autor).

Já a função enunciador é por Ducrot concebida como a origem dos pontos de vista mobilizados e atualizados pelo locutor no enunciado. Para ele (1990, p. 19), "todo enunciado presenta un cierto número de puntos de vista relativos a las situaciones de las que se habla".

Ainda nesse texto, Ducrot (1990, p. 66-67) esclarece que o locutor (L) pode adotar três atitudes em relação aos pontos de vista (os enunciadores) que atualiza no enunciado: (a) pode identificar-se com um dos enunciadores ou assumi-lo, como em uma asserção, "el locutor se identifica con un enunciador si da a su enunciación (o más exactamente, hace como si diera a la 
enunciación) el objetivo de imponer el punto de vista de ese enunciador"; (b) pode dar aprovação a um enunciador ou aceitá-lo mesmo quando o enunciado não tem como finalidade fazer admitir o ponto de vista desse enunciador, como ocorre na pressuposição em que não há como o locutor assumir o posto sem aceitar o pressuposto; e (c) pode se opor a um enunciador e recusar-lhe o ponto de vista, é o caso do humor, por exemplo, em que "L presenta un punto de vista absurdo que él mismo rechaza sin presentar ningún otro punto de vista susceptible de corregir el primero".

Descrever o sentido de um enunciado por essa versão da TP demanda, então, verificar: se o enunciado contém a função locutor (o que não acontece, segundo Ducrot (1990:19), com os provérbios, por exemplo); quais são os enunciadores atualizados por L no enunciado; e que atitude é adotada por $\mathrm{L}$ em relação ao ponto de vista de cada enunciador mobilizado.

Feita essa sintética exposição acerca da Teoria da Polifonia, pretendo mostrar como penso que essa teoria possa ser didaticamente transformada em "mecanismo" capaz de aprimorar e maximizar o desenvolvimento da compreensão leitora dos usuários de uma dada língua.

\section{Polifonia linguística: exemplo de transformação didática}

Utilizarei para constituir o exemplo anunciado no título deste tópico um discurso, e as respectivas questões destinadas à sua compreensão, retirado de um livro didático destinado a alunos do $6^{\circ}$ ano do Ensino Fundamental. Por motivos éticos, reservo-me o direito de não referir o livro, só preciso dizer que foi recomendado pelo Plano Nacional do Livro Didático (PNLD) de 2008.

A imagem que segue apresenta o referido discurso e as questões de compreensão.

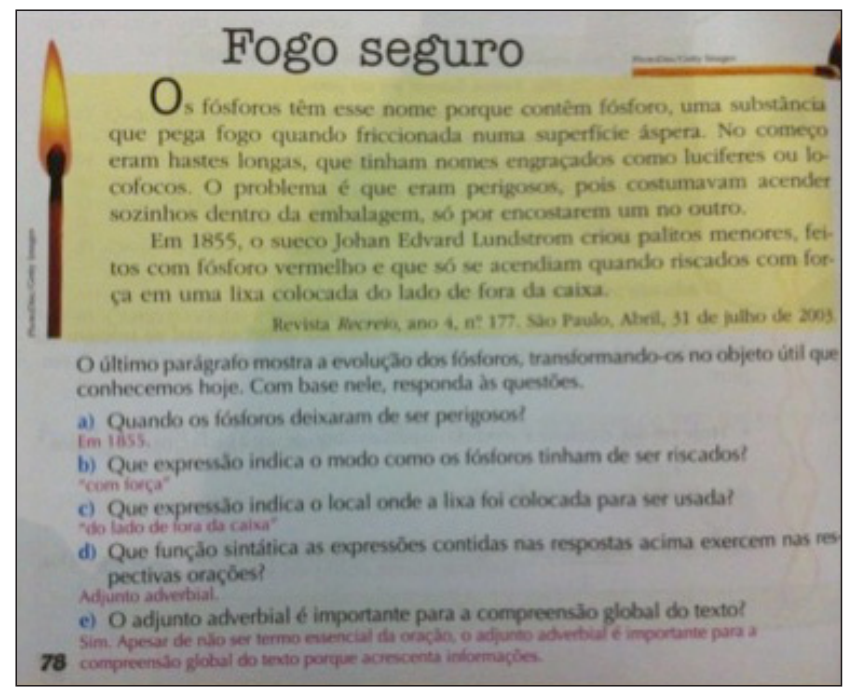

Das cinco questões formuladas, as três primeiras só exigem do aluno que localize as informações no parágrafo indicado e as copie como resposta a cada pergunta; as duas últimas tratam explicitamente da função sintática que as expressões-resposta das três primeiras perguntas "exercem nas respectivas orações". Ora, como bem sabemos um discurso não é uma soma de enunciados, muito menos uma soma de entidades gramaticais chamadas orações. Aqui temos a primeira inadequação, inclusive teórica, das questões acima. Além disso, como já referi no início deste artigo, não creio que classificação gramatical contribua para o desenvolvimento das habilidades exigidas pela compreensão leitora.

Por falar em compreensão, convido o leitor a observar a resposta sugerida (por se tratar de um livro dirigido ao professor) para a última questão. Como um termo não essencial da oração pode ser importante para a "compreensão global do texto"? Se o foco é a compreensão chamada "global", como pode um "termo" expresso no discurso não ser essencial à sua compreensão e, ainda assim, acrescentar informações? Qual é o "termo" em um discurso que não "acrescenta informações"? Se o foco de estudo são categorias sintáticas (adjunto adverbial e oração), como é possível afirmar que elas colaboram para a "compreensão global" de um discurso, uma vez que categorias gramaticais, como qualquer outro construto teórico, não atuam no sentido de entidades linguísticas concretas como o discurso? Deixo ao leitor as respostas a essas questões.

Utilizando o mesmo trecho do discurso objeto das perguntas no referido livro didático, tento mostrar agora como poderiam ser elaboradas questões que, por meio da explicitação da polifonia constituidora do seu sentido, pudessem auxiliar o aluno a desenvolver a compreensão leitora.

Transcrevo o referido parágrafo para facilitar ao leitor a análise do que estou propondo:

Em 1855, o sueco Johan Edvard Lundstrom criou palitos menores, feitos com fósforo vermelho e que só acendiam quando riscados com força em uma lixa colocada do lado de fora da caixa.

Usarei, igualmente, o mesmo enunciado para a atividade só para mostrar como é possível dar à compreensão um enfoque polifônico.

\footnotetext{
O último parágrafo mostra a evolução dos fósforos, transformando-os no objeto útil que conhecemos hoje. Com base nele, responda às questões.

a) Quanto ao tamanho, como eram os palitos de fósforo antes de 1855?

b) Equanto à cor?

c) Que palavra mostra que anteriormente os palitos podiam incendiar sem serem riscados?

d) É possivel dizer que os palitos criados por Lundstrom acendiam facilmente ao entrar em contato com uma lixa? Por quê?

e) Que expressão indica que em 1855 os palitos de fósforo já eram embalados em caixas?
} 
A tônica das questões por mim elaboradas é a explicitação dos enunciadores atualizados pelo locutor desse trecho do discurso em análise, a fim de que o aluno compreenda o que está dito sem estar manifesto. Ao responder cada pergunta, o leitor é chamado a dar-se conta dos vários pontos de vista mobilizados pelo locutor para a constituição do sentido do discurso. Será possível ao professor dizer que um aluno que só compreende o que estiver explícito no discurso é um leitor proficiente?

O próprio Guia de livros didáticos 2014, do PNLD, ao abordar a avaliação de atividades de leitura, recomenda o trabalho com a polifonia.

O que deve ser considerado para avaliar as atividades de leitura?

[...] a exploração de propriedades textuais e discursivas: unidade e progressão temática; articulação entre partes; modos de composição tipológica; intertextualidade e polifonia; argumentatividade; planos enunciativos; relações e recursos de coesão e coerência; relações entre o verbal e o não verbal em textos multimodais $\mathrm{e}$ dimensões sociolinguísticas presentes no texto. (GLD, 2014, p. 42)

Agora, analisemos, rapidamente, como cada uma das questões propostas põe em evidência a polifonia linguística.

Para responder a primeira questão, o aluno precisará compreender que, se o enunciado diz quer Johan Edvard Lundstrom criou palitos menores, é porque há um enunciador aceito pelo locutor L que diz que antes dessa criação os palitos eram maiores.

Da mesma forma, a segunda questão exige do aprendiz que compreenda o enunciador, igualmente aceito por L, que afirma que antes dessa invenção os palitos eram feitos com fósforo não vermelho, pois no enunciado está dito que os criados por Lundstrom eram feitos com fósforo vermelho.

A terceira questão solicita ao aluno a compreensão de que a palavra só marca um outro ponto de vista: o de que os palitos anteriores aos criados por Lundstrom acendiam sem terem sido riscados.

A justificativa para resposta negativa prevista para a quarta questão só será possível ao aluno se ele compreender que os palitos inventados têm como condição para acenderem o fato de serem riscados com força, o que novamente permite localizar um enunciador mobilizado por L como antes dos de Lundstrom os palitos de fósforo acendiam simplesmente ao entrar em contato com uma lixa.

Ao indicar o local em que era fixada a lixa para que os palitos fossem riscados, $\mathrm{L}$ põe à mostra um enunciador do tipo Os palitos de fósforo eram embalados em caixas, o que necessita ser compreendido pelo aluno para responder à quinta questão.
Obviamente, por esse exemplo, apresentei apenas uma proposta inicial de aplicação didática da polifonia linguística, mas a semente está lançada e, com certeza, em terra fértil.

\section{Algumas considerações a mais}

Preciso ainda relatar o depoimento de uma aluna do $1^{\circ}$ ano do Ensino Médio a quem submeti as questões por mim formuladas e que teve muita dificuldade em respondê-las. Horas depois da atividade, perguntada por sua mãe sobre como julgava tais questões, a aluna disse tê-las achado muito difíceis, porém disse ter pensado que, se tivesse sido ensinada a ler assim (como as questões o exigiam), ficaria mais fácil inclusive estudar as demais disciplinas do currículo.

Desse relato, me permito destacar dois pontos: o fato de, no Ensino Médio, um aluno dizer e demonstrar ter tanta dificuldade para responder questões destinadas ao $6^{\circ}$ ano do Ensino Fundamental; e o fato de (como sempre pensei, aliás) um aluno saber avaliar o que deveria ser feito para que aprendesse a ler, bem como as consequências de tal aprendizagem para o estudo em outras disciplinas além da de língua materna.

Gostaria imensamente que os professores da Educação Básica se dispusessem a ouvir mais seus alunos quanto às formas pelas quais eles acreditam aprender mais eficazmente.

Espero ter conseguido mostrar aqui como vejo a transformação didática da Teoria da Polifonia em "mecanismo" para o desenvolvimento da compreensão leitora. Mesmo com a brevidade que um artigo como este impõe, me foi possível, ao menos, pôr em discussão o uso didático da polifonia linguística no que diz respeito ao desenvolvimento da compreensão leitora.

\section{Referências}

ÁLVAREZ, Teodoro. Didáctica del texto en la formación del professorado. Madrid: Síntesis, 2005.

AZEVEDO, Tânia M. de. Outras vozes na argumentação: atualização da polifonia e reformulação da descrição semânticoargumentativa do discurso. Letras de Hoje, Porto Alegre, v. 46, n. 1, p. 64-72, jan.-mar. 2011.

AZEVEDO, Tânia M. de. Transposição didática de gêneros discursivos: algumas reflexões. Desenredo - Revista do Programa de Pós-Graduação em Letras da Universidade de Passo Fundo, v. 6, n. 2, p. 198-214, jul.-dez. 2010.

Brasil. Secretaria de Educação Fundamental. Parâmetros curriculares nacionais: terceiro e quarto ciclos do ensino fundamental: língua portuguesa/Secretaria de Educação Fundamental. Brasília: MEC/SEF, 1998.

CHEVALLARD, Yves. La transposición didáctica: del saber sabio al saber enseñado. Buenos Aires: Aique, 1991. 
DUCROT, Oswald. Polifonía y argumentación - conferencias del seminario Teoría de la Argumentación y Análisis del Discurso. Cali, Universidad del Valle, 1990.

DUCROT. O dizer e o dito. Campinas, SP: Pontes, 1987.

DUCROT. Les mots du discours. Paris: Minuit, 1980.

Guia de livros didáticos: PNLD 2014: língua portuguesa: ensino fundamental: anos finais. Brasília: Ministério da Educação, Secretaria de Educação Básica, 2013. Disponível em: <http:// www.fnde.gov.br/programas/livro-didatico/guias-do-pnld/ item/4661-guia-pnld-2014>. Acessado em: 14 nov. 2014.

POZO, J. I. Aprendizes e mestres. Porto Alegre: Artmed, 2002.

TEIXEIRA, Marlene. É possível a leitura? Revista Nonada, UniRitter, Porto Alegre, ano 8, n. 8, p. 195-204.

Recebido: 15 de agosto de 2015.

Aprovado: 16 de outubro de 2015.

Contato: tmazeved@ucs.br 